\title{
Social Support and Life Satisfaction among Entrepreneurs: A Latent Growth
}

\section{Curve Modelling Approach}

3
Safiya Alshibani, University of Western Australia

Thierry Volery, Zurich University of Applied Sciences (ZHAW)

\section{Abstract}

Purpose: Social support has been identified as a valuable resource that could help entrepreneurs maintain goal directness in their endeavours and increase their life satisfaction. However, to date scant research has examined the effect of perceived social support on life satisfaction during the transition from paid employment to self-employment. This paper uses the Job Demand Resource Model (JD-R) as a theoretical lens to investigate this relationship.

Methodology: Drawing on the Household Income and Labour Dynamics in Australia (HILDA) ${ }^{1}$ survey, we use latent growth curve modelling (LGCM) to investigate the trajectories of entrepreneurs' perceived social support and life satisfaction $(n=1,303)$ up to five years after their transition into self-employment.

Findings: Results suggest that entrepreneurs experience a boost in life satisfaction in the transition phase, followed by a declining trend in the years that follow. We find that both the initial perception and the evolution of perceived social support are positively related to life satisfaction over time across gender groups. However, we find that females may benefit more from early social support soon after the transition into self-employment to forestall declines in life satisfaction over the long-term.

Originality/value: This study extends the JD-R literature by examining the transition into selfemployment, considered an "active job" characterised by high demands and high decision latitude. LGCM modelling captures how both initial levels and changes in social support affect life satisfaction during entrepreneurship entry and over time.

Research limitations/implications: The generalisability of the research findings beyond the Australian context is undefined. Future research needs to examine to what extent these results can generalize to other samples within different cultural and institutional frameworks.

Practical implications: Since perceived social support is a strong buffering mechanism that helps mitigate job demands, entrepreneurs need to be proactive in building a strong network. Individuals who switch to self-employment should carefully map and build a strong social network that can help them weather the challenges and setbacks in their new job.

\footnotetext{
1 This paper uses unit record data from the Household, Income and Labour Dynamics in Australia (HILDA) Survey. The HILDA Project was initiated and is funded by the Australian Government Department of Social Services (DSS) and is managed by the Melbourne Institute of Applied Economic and Social Research (Melbourne Institute).
} 
37 A considerable amount of research effort has been expended on improving our understanding of entrepreneurs' life satisfaction in recent times (Binder, 2018; Dijkhuizen et al., 2017; Georgellis and Yusuf, 2016: van der Zwan et al., 2018). These studies have shown that entrepreneurs are in general more satisfied with their lives than paid workers are. Scholars attribute this markedly higher satisfaction to the job of the entrepreneur being characterised by autonomy, flexibility, skill utilisation and a greater variety of tasks (Benz and Frey, 2008; Blanchflower, 2000).

Recent research has focused on within-individual variation of the returns to entrepreneurship, investigating individual entrepreneurs as they transition into self-employment (Chadi and Hetschko, 2017; van der Zwan et al., 2018). This stream of literature suggests that entrepreneurs enjoy only a temporary boost in job satisfaction during the transition phase. Over time, they go back to the base line 'adaption process' once the 'honeymoon-hangover effect' dissipates (Georgellis and Yusuf, 2016; Hanglberger and Merz, 2015). The same pattern of trajectory applies to life satisfaction (Binder and Coad, 2013, 2016; van der Zwan et al., 2018).

Quitting paid employment to start a new venture can be a very lonely experience (Stephan, 2018). In addition, entrepreneurship is like a rollercoaster journey where breakthroughs are interspersed with numerous failures, setbacks and near misses (Clarke and Holt, 2016). In this context, social support has been identified as a key resource to help entrepreneurs cope with stressful situations (Boz Semerci and Volery, 2018; Davidson et al., 2010). This concept captures the individual's perception that he or she is cared for, valued, and has people on whom they can relate to at the time (Zhu et al., 2017). Social support helps entrepreneurs to share a wide range of issues with others, to obtain empathy and to try out new perspectives and ideas (Boz Semerci and Volery, 2018).

Drawing on the Job Demands-Resources (JD-R) model (Bakker and Demerouti 2007; 61 Demerouti and Bakker, 2011), the objective of this study is to investigate the role of perceived social support (PSS) on life satisfaction during entrepreneurship entry. Specifically, we posit that PSS is an important resource and we examine whether the initial level of PSS and its evolution over time affects entrepreneur life satisfaction during the transition into selfemployment and beyond. Furthermore, recognising the influence of gender on vocational behaviour (Ahl, 2006; Marlow, 1997) and support-relevant social interactions (Eagly, 1997; 
67 Matud et al., 2003), we examine gender differences around the nexus of entry into selfemployment, PSS, and life satisfaction.

69 Entrepreneur well-being is an area of research still in its infancy, with studies mainly from the economics and labour economic disciplines (Georgellis and Yusuf, 2016; van der Zwan et al., 2018). The recent years have seen a shift in focus away from comparing well-being across individuals to comparing within individuals over time, motivated by increased availability of longitudinal data and the need to gain insight into the rate of change and how initial PSS levels affect an entrepreneur's subjective well-being over time. In this study, we adopt the hedonic approach to subjective well-being (Stephan, 2018), namely life satisfaction, and we use both terms interchangeably. This approach characterises well-being through the attainment of pleasure, avoidance of pain, and satisfaction with various domains of life.

The contribution of the study is threefold. Firstly, at a theoretical level, this study extends the JD-R literature by examining the transition into self-employment, considered an 'active job' characterised by high demands and high autonomy. In this context, our results suggest that job decision latitude only partly buffers against the negative effects of high demands on entrepreneur life satisfaction and that social support is a key resource to maintain satisfaction. Secondly, from a methodological perspective, we adopt a sophisticated modelling approach, namely Latent Growth Curve Modelling (LGCM), to explore the trajectory of life satisfaction among entrepreneurs. Our study assesses within-individual variation of the returns from entrepreneurship, which effectively eliminates unobservable pooling effects (Åstebro and Chen, 2014). In addition, the method allows us to simultaneously investigate how initial levels and changes in social support relate to life satisfaction. Thirdly, our approach provides a longitudinal perspective on entrepreneur well-being. This is critical since entrepreneurship is a long-term process which requires an understanding of the evolution of the rewards before and after entrepreneurship entry (Clarke and Holt, 2016). We draw on 16 waves from the Household, Income and Labour Dynamics in Australia (HILDA) survey and follow within this period individual PSS and life satisfaction trajectories for up to five years after a transition into self-employment. 


\section{Theoretical anchor and hypothesis development}

\subsection{Job Demands-Resources and life satisfaction of entrepreneurs}

The Job Demands-Resources (JD-R) model (Bakker and Demerouti, 2007; Demerouti and Bakker, 2011) provides a theoretical lens for conceptualising the characteristics of selfemployment and their implications for life satisfaction. Broadly conceived, it proposes that well-being across occupations, after controlling for personality, stems from two general job related sources: job demands and job resources (Bakker et al., 2010). Job demands refer to the physical, psychological, social and organisational aspects of a job that require sustained physical, mental and emotional effort and are therefore associated with physiological costs such as stress or exhaustion (Bakker et al., 2007; Nahrgang et al., 2011). Examples of job demands include conflicting demands, job ambiguity, workload, and time pressure. Conversely, job resources refer to physical, psychological, social and organisational aspects of the job that help achieve work goals, reduce job demands and the associated physiological or psychological costs, or, stimulate learning and personal development (Bakker et al., 2007; Schaufeli and Bakker, 2004). Examples of job resources include autonomy, social support and performance feedback.

JD-R theory draws on the well-established Job Demand-Control (JDC) model (Karasek, 1979), which states that two occupational characteristics of the work environment, job demand and job control, interact to influence worker well-being and health. In addition to the aforementioned job demands, JDC considers job control, the decision latitude over job performance that relates to factors such as how and when a job task is completed. The basic prediction of the JDC model is the 'strain hypothesis': job demand increases work-related stress, whereas job control decreases it in an additive fashion. The second prediction, in line with the first prediction, is the 'buffer hypothesis', which entails a multiplicative effect of job demand and job control on well-being (van der Doef and Maes, 1999), in such a way that control can moderate the negative effects of high demands on well-being. In other words, job control enhances one's feelings of being able to cope with job demands (Karasek, 1979). JDC suggests that the most detrimental consequences on well-being arise when the psychological demands of the job are high and the decision latitude of the worker is low (Theorell and Karasek, 1996).

JD-R expands the JDC model by reasoning that different job resources, not just control, can act as buffers for a variety of different job demands (Bakker et al., 2005). The central 
assumption in the JD-R Model is that work-related strain develops when certain job demands are high but job resources are limited, undermining well-being and work engagement (Bakker et al., 2007). In contrast, when job resources are high, the motivational process is activated,

130 leading to work engagement and higher work performance (Schaufeli and Bakker, 2004;

131 Bakker et al., 2005).

132 Self-employment typically combines high decision control and high job demand, a situation 133 characterised as an 'active job'. Running your own business entails autonomy, flexibility, task 134 identity and task variety, all of which can potentially induce higher job satisfaction (Benz and 135 Frey, 2008; Blanchflower, 2000). In addition, entrepreneurship enhances subjective well-being 136 by meeting vital psychological needs. It has been suggested that freedom and autonomy 137 provide a 'procedural utility', as entrepreneurs value not so much the outcomes, but the 138 conditions and processes leading to these outcomes (Benz and Frey, 2004). Thus, entrepreneurs 139 derive happiness from being able to do what they like (Nikolova, 2018).

140 Nonetheless, self-employment is a high-demand job. Entrepreneurs tend to work longer and 141 more irregular hours than employees (Åstebro and Chen, 2014; Levine and Rubinstein, 2012); 142 and their work is characterised by high pace, brevity and fragmentation. Entrepreneurs running 143 a business with employees must also cope with multiple demands and diverging expectations 144 (Cowling et al., 2004). Self-employment could worsen life satisfaction if it entails loneliness, 145 reduced socialisation, immersion in business, and the pressure to achieve (Cardon and Patel, 146 2015; Jamal, 1997). However, in 'active jobs' the combination of high job control with high 147 job demand leads to 'desirable stress' (Karasek, 1979; Theorell and Karasek, 1996), as 148 individuals are likely to learn new things and develop new skills. Therefore, self-employment 149 can be considered as motivating and stimulating, and this reduces the downward impacts on 150 life satisfaction.

151 Although the literature provides considerable support for the strain hypothesis, support for the 152 buffer hypothesis - stating that control can moderate the negative effects of high demands on 153 well-being - is less consistent (Binder and Coad, 2016; van der Zwan et al., 2018; van der Doef 154 and Maes, 1999). This suggests that job control only partly buffers against the impact of job 155 demands on entrepreneur well-being.

156 As nascent entrepreneurs pass the initial euphoric launch stage and struggle to establish their 157 business, many of them realise the gruelling reality of self-employment and that their venture 158 may end up failing. This scenario is particularly plausible because of the overt optimism 
characterising most self-employed individuals (Cassar, 2010). In this vein, The Economist

160 (2014, p. 66) remarked: "It is fashionable to romanticize entrepreneurs. But the reality can be as romantic as chewing glass: first-time founders have the job security of zero-hour contract workers, the money worries of chronic gamblers and the social life of hermits." As the harsh reality of running their own business becomes apparent, entrepreneurs are likely to experience a decline in life satisfaction, bringing it back to the baseline (Georgellis and Yusuf, 2016).

Recent empirical studies suggest that while individuals experience a boost in satisfaction when entering self-employment, this feeling declines in the years following the transition to selfemployment (Hanglberger and Merz, 2015; van der Zwan et al., 2018). The organizational psychology literature called this short-lived spike "the honeymoon effect" (Boswell et al., 2005), capturing the effect of a new job in general. Using the German Socio-Economic Panel Study, Chadi and Hetschko (2017) identified a similar 'anticipation and adaption effect' when studying job satisfaction. In the same vein, van der Zwan et al. (2018) found few rewards in terms of life satisfaction, and that higher work satisfaction may come at the cost of decreased individual satisfaction in the important life domain of leisure. Thus, we hypothesize that

H1: When switching from paid to self-employment, entrepreneurs will experience an immediate boost in their life satisfaction and then a decline over time.

\subsection{Perceived social support}

177 JD-R research indicates that effective buffering takes place when job demands and resources

178 (and not only control) interact to predict engagement, which enhances well-being. A high level

179 of control over the work situation, manageable work demands and pertinent resources are 180 crucial factors an employee needs to be able to experience for a high level of job and life 181 satisfaction (de Lange et al., 2003; van Woerkom et al., 2016). We posit that social support is a key resource for entrepreneurs attempting to cope with stressful situations, especially during the transition into self-employment, when they leave their familiar work environment and coworkers to start a venture on their own.

PSS refers to an individual's perception of the support acquired from their environment. It is a complex construct that encompasses a sense of connection and relatedness (Barrera, 1986).

187 PSS can either be emotional, material, or informational (Keat et al., 2011). It is an individual's 188 perception of receiving support which is critical; in fact, research indicates that perceived 
support contributes just as much to health and well-being outcomes compared to the existence of actual support (i.e. received social support) (Lakey, 2013).

191 In addition, the entrepreneur's direct or tacit support from social ties contributes significantly to his or her success in business (McDowell et al., 2019). For instance, social support increases

193 the chance of business survival and helps the entrepreneur in manoeuvring various business

194 hurdles that come in the form of financial constraints or legal troubles (Kar, 2017). Similarly, 195 social support provided by family members reduces the exit likelihood from entrepreneurship 196 (Revilla et al., 2016; Zhu et al., 2017). Without adequate social support systems, entrepreneurs 197 find it harder to succeed as they will have to rely on their (limited) own knowledge and expertise (Bird and Wennberg, 2016).

199 We recognise the potential bidirectionality between social support and life satisfaction.

200 Individuals who receive social support are likely to experience greater life satisfaction, but the 201 level of life satisfaction may also cause changes in perceptions of social support. Because the 202 impetus behind this research is to identify the buffering mechanism of PSS during entrepreneurship entry (rather than the longitudinal causality between PSS and well-being), we posit that social support drives well-being outcomes. Specifically, we propose that people will enter self-employment with different levels of PSS, and that those who initially report higher levels will have a higher life satisfaction. A high level of PSS will slow down the decline in life satisfaction, once entrepreneurs pass the "honeymoon phase" in the years following the transition to self-employment. Thus,

209 H2a: The initial level of social support will positively influence the initial level of life 210 satisfaction.

211 H2b: Social support will slow down the declining slope of life satisfaction in the years 212 following the transition into self-employment.

\section{2.3. Gender perspective}

214 A vast stream of the literature in entrepreneurship suggests that female entrepreneurs and the 215 characteristics of their ventures are significantly different from that of men (Ahl, 2006). Among 216 other things, female founders report being more satisfied with their business in comparison to 217 male entrepreneurs (Carree and Verheul, 2012; Crum and Chen, 2015).

218 However, the transition into self-employment poses a number of challenges for female 219 entrepreneurs. Traditional gender norms appear to be strongly reflected amongst the self- 
employed (Ahl, 2006). Eib and Siegert (2019, p. 1) recently remarked in this respect that, "Many women-operated firms reflect feminized working patterns, such as working part-time or basing the business within the home, which, as a result, reinforces the perception of women as mothers and care-takers first". This view follows social role theory (Eagly, 1997), suggesting that men are more likely to fulfil roles outside the home and be the main breadwinner, whereas women are generally responsible for childrearing and other domestic tasks. Because of the demands associated with their dual role of child-rearing and entrepreneurship, women tend to experience a higher prevalence of work-family conflicts and parenting stress (Cabrera and Mauricio, 2017; Marlow, 1997).

In addition, women are more likely to experience financial and social stressors during a business launch. Chadwick and Raver (2019), found that female entrepreneurs tend to feel more stressed when they face high financial need and when they perceive low social support in their environment. These higher stress appraisals among women persist several months later during business operation compared with their male counterparts (Chadwick and Raver, 2019). Against this backdrop, social support is a key resource to help coping with stressful situations (Boz et al., 2018). However, a gender-stratified analysis reveals a different pattern between males and females in respect to social support and its impact on life satisfaction. Firstly, empirical studies suggest that women have more extensive, better and varied social relations than men (Fuhrer and Stansfeld, 2002). They provide and receive more support and have a wider "net of concern" than men; that is to say, they spend more time involved in responding to requests and support from other people (Johansson et al., 2016). Furthermore, women have a greater propensity to seek social support especially during stressful events and they can more readily mobilise support when in need (Liebler and Sandefur, 2002). Women also have larger social networks outside of work (Johansson et al., 2016).

244 Secondly, women tend to perceive, seek, and use social support differently. For example, when examining the differences between genders with respect to the effect of perceived job demands, control, and support, Rivera-Torres et al. (2013) found that social support has a stronger weakening effect on the levels of job stress for women than men. Thus, we formulate the following hypothesis:

249 H3a: Female entrepreneurs will gain a larger increase in life satisfaction from perceived social support than men when entering self-employment. 
251 H3b: Over time, the effect of perceived social support on life satisfaction will be stronger for female entrepreneurs than for male entrepreneurs.

\section{Data and method}

254 This study draws on 16 waves of Household, Income and Labour Dynamics in Australia (HILDA) survey data. This nationally representative household-based panel study began in 2001 and covers around 9,835 households. Entrepreneurs were identified based on their occupational status, and we use the terms 'entrepreneurs' and 'self-employed' interchangeably. Our definition of self-employment follows Wooden and Watson (2007), in that it includes all types of entrepreneurs regardless if they had incorporated their business or not. In other words, both owner-managers who operate their own incorporated businesses and people who operate their own unincorporated business were included in the study.

262 Further, we define entrepreneurship transition as the change in the occupational status from one year to the next, i.e change from paid employment in year (t) to being self-employed in year $(t+1)$. This identification approach is customary in economics and entrepreneurship research (Nikolova, 2018; van der Zwan et al., 2018). A total of 2,711 individuals who made the transition from paid employment to self-employment at some stage (unbalanced panel) were identified. In a second stage, 467 observations involving multiple spells of selfemployment were excluded; this focus helps us filter out "job hoppers" (Failla et al., 2017).

269 The baseline for the analysis was set to one year before the transition to self-employment and

270 five years after the transition; This baseline provides an optimal initial status measure to consider the impact of PSS in shaping the trajectories of life satisfaction. Those who change their status between waves to any other labour status but self-employment were excluded automatically. Of the original sample, 39\% remained self-employed in the fifth year. To capture the (linear or non-linear) trajectory after the transition into self-employment and the parallel processes of PSS and life satisfaction, any individual with less than four waves of measurement was excluded. This procedure was intended to identify true change from measurement errors (Preacher et al., 2008). Following these different steps, the final sample included 1,303 individuals. Missing data arising from this sampling strategy are discussed in the results section. 


\subsection{Measurement}

281 Life satisfaction was measured using self-reported level of satisfaction with life on a scale from 0 (completely dissatisfied) to 10 (completely satisfied). The exact question was "All things considered, how satisfied are you with your life?" and it was included in all waves of HILDA. This single item was adopted in several past studies (Benz and Frey 2008; Blanchflower, 2000), and it is considered very similar to more psychometrically established multiple-item scales (Andersson, 2008; Binder and Coad, 2016; Binder, 2018). Following Hahn's et al. (2015) approach, we mean-centred the life satisfaction score within each wave in relation to the average value for the total HILDA sample. This procedure allows controlling for any other major life events and facilitates the interpretation of the coefficients. Further, the trend of the centered scores followed the same trend as the raw data averages over time, implying the absence of any systematic changes that could have been hidden by the centering procedure.

PSS was measured with 10 items (Table 1) capturing the entrepreneur's beliefs and expectations about the assistance and advice that he/she may receive from his/her social groups. The construct was measured using a seven-point Likert scale $(1=$ strongly disagree to $7=$ strongly agree). The first seven items were adopted from Henderson et al. (1978), while the last three items were from Marshall and Barnett (1993). Confirmatory factor analysis was applied and confirmed the factorial invariant across measurement waves with acceptable fit $(\mathrm{CFI}=0.93, \mathrm{TLI}=0.92, \mathrm{RMSEA}=0.034)$ and a significant $\chi^{2}$ difference test compared to the fully constrained model $\left(\triangle \chi^{2}(78)=214.663, \mathrm{p}<0.001\right)$. The factor scores were calculated by weighting items based on the factor loadings from the CFA, with a higher score indicating that a person perceives to have a strong social support.

- Insert Table 1 here -

\subsection{Statistical analysis}

The Latent Growth Curve modelling (LGCM) technique was used to examine the intraindividual change and inter-individual change over time (Preacher et al., 2008). LGCM helps to circumvent limitations of past studies on life satisfaction, which relied on fixed effect regression analysis. These studies have been unable to examine social support and life satisfaction together in a single model except by splitting the sample into low and high social support categories. Recent studies (e.g. Milner et al., 2016) typically used fixed effect regression to examine the effect of perceived social support on mental health for employed and 
unemployed individuals. However, these studies were not able to explain the dynamic of the

313 developmental processes of social support and mental health over time using regression.

314 LGCM offers several advantages. Firstly, it allows researchers to simultaneously investigate 315 how initial levels and changes in PSS are linked to life satisfaction. Secondly, LGCM 316 techniques estimate the average rate of change of the sample over time, as well as the variability 317 of that change within the sample. This facilitates understanding of both the average change in 318 life satisfaction among entrepreneurs and also the individual variation, shedding some light 319 about the role PSS plays and why some entrepreneurs experience changes and others do not 320 (i.e the individual differences in initial status and in the growth over time). Thirdly, LGCM has 321 the capability to explicitly assess and model measurement error variance at particular time 322 points (Preacher et al., 2008). Finally, LGCM can reduce the bias introduced by attrition rate which is expected in longitudinal studies (Curran et al., 2010).

324 In implementing LGCM, we followed a two-step procedure (Preacher et al., 2008). The conceptual model is shown in Figure 1. In the first step, we measured the changes in PSS and life satisfaction over the course of five years after the transition into self-employment. Unconditional LGCM models were computed separately for PSS and life satisfaction. In LGCM, the intercept describes the initial values of the variable, and since it is constant for each subject over time, it has a factor loading of 1 . The slope describes change over time, which can take a linear or non-linear developmental form. Several forms of growth were tested: (1) a free LGCM with unspecified growth function which allowed us to freely estimate the slope means and determine the best fit based on the data (i.e., the parameterization of time in the factor loading matrix were freely estimated after the transition $-1, *, *, *, *, *$, and 1$)$; (2) a linear LGCM that tested the assumption of a linear increase or decrease in the construct (i.e., fixing the loadings of the slope to $0,1,2,3,4,5,6)$; and (3) a quadratic LGCM by adding a quadratic slope (i.e., fixing the loadings to $0,1,4,9,16,25,36$ ) testing the assumption that the construct followed a curvilinear pattern.

338 In the next step, in order to investigate the extent to which entrepreneur PSS predicts the level of and the changes in life satisfaction, a parallel process model was computed. This captured the developmental process of the two latent variables simultaneously. Finally, a parallel process model was testing differences between females and males. 
344 The following fit indexes are reported: $\chi^{2}$, Root Mean Squared Error of Approximation

345 (RMSEA), Akaike's Information Criterion (AIC), Bentler Comparative Fit Index (CFI), and

346 Tucker Lewis Index (TLI). For RMSEA, a value less than .05 will be taken as evidence of a 347 good fit. For AIC, the lower the value the better fit. Both CFI, and TLI values greater than 0.95

348 indicate excellent fit. All analyses were conducted using the maximum likelihood estimation,

349 a suitable approach to handling missing observations in AMOS 25 (Arbuckle, 2014).

$350 \quad 4 . \quad$ Results

$351 \quad$ 4.1. Sample Characteristics and preliminary analysis

352 Table 2 reveals that the average age of participants in the year before the transition was 39, and the majority (64.9\%) were male. The level of educational attainment was as follows: $13.6 \%$

354 postgraduate degree, $26.6 \%$ undergraduate degree, and the majority (59.8\%) had a vocational 355 degree or had completed high school. The average income in the baseline year was around 356 A \$10,430. The majority of people (55.5\%) in our sample were married and the minority (15\%) 357 were suffering from a long-term health condition, and $35.1 \%$ of people in the sample did not 358 have children.

359 As stated previously, since LGCM uses maximum likelihood estimation, it does not require 360 complete data to estimate an average intercept and rate of change. Therefore, missing data do 361 not affect the parameter estimate (Curran et al., 2010). However, a minimum of four 362 observations was deemed necessary to establish the trajectory. Missing data analysis was 363 conducted to identify any substantial baseline differences between the included $(\mathrm{n}=1,303)$ and 364 excluded data $(\mathrm{n}=870)$ (Table 3). Compared with entrepreneurs in the analytic sample, those 365 who had less than four waves of data were younger, mostly female, with lower income, and 366 lower educational attainment. However, all the aforementioned differences are marginal, with 367 a small effect size.

368

- Insert Table 2 here - 


\subsection{General trends}

Figure 2 and 3 illustrate the general trend in PSS and life satisfaction based on the raw average score. PSS decreased in the first two years after the transition and levelled up after the third year. Furthermore, PSS remained almost constant for both genders. However, women reported higher levels of PSS compared to men. The trend for life satisfaction indicates that the means generally increased over the first period of the transition. The biggest positive change occurred in the first year after transition and increased at a slower rate thereafter. In terms of the average life satisfaction, there is a different pattern of change by gender. Figures 2 and 3 suggest that there is sufficient variability in PSS and life satisfaction scores for testing the parallel process model.

- Insert Figure 2 here -

- Insert Figure 3 here -

\subsection{Unconditional LGCM social support}

The Likelihood ratio tests for nested models (Table 4) were applied to determine which model provided the best fit to the data. The linear model was adapted for its parsimony and consistency with other models used in developmental studies (Pettit et al., 2011). The linear LGCM for social support matched the data well $\left(\chi^{2}=36.245\right.$, $\mathrm{df}=23$, RMSEA $=0.021$, $\mathrm{TLI}=0.995, \mathrm{CFI}=0.996, \mathrm{AIC}=60.245)$. The intercept's mean was around 0.005 and the slope's mean indicated a non-significant general change over time $(-0.034 ; p=0.320)$. Furthermore, the initial start and rate of change were heterogeneous among the group given the significant variance around the mean slope $(0.005 ; \mathrm{p}<0.001)$ and the mean intercept $(0.604 ; \mathrm{p}<0.001)$. The estimated covariance between the slope and intercept was not significant $(-0.007 ; \mathrm{p}=$ 0.122), suggesting that the rate of decline in perceived social support over time was similar for individuals who initially started with either high or low scores.

Running a multi group LGCM by gender reveals interesting results. Females have a slightly upward trajectory as indicted by the mean intercept $(-0.002 ; p=0.831)$ and mean slope $(0.175$; $\mathrm{p}<0.001)$. In contrast, males have a declining trajectory suggested by the mean intercept $(0.009, p=0.160)$ and mean slope $(-0.150 ; p<0.001)$. The analysis of variance in the trajectory of both males and females showed a significant variation in the initial start $(0.594, \mathrm{p}<0.001$ for males, $0.554, p<0.001$ for females) and rate of change $(0.006, p<0.001$ for males, 0.003 , $\mathrm{p}<0.001$ for females). 
405

406

407

408

409

410

411

412

413

414

415

416

417

418

419

420

421

422

423

424

425

426

427

428

429

430

431

432

433

Among the several forms of growth tested (Table 4), the free LGCM was selected, where the optimal growth trajectories can be determined from the observed data $\left(\chi^{2}=35.579\right.$, df $=19$, $\mathrm{RMSEA}=0.031, \mathrm{TLI}=0.993, \mathrm{CFI}=0.996, \mathrm{AIC}=64.269)$. The free LGCM best captures the complexity of the observed trajectories within the data; it describes the boost and downturn over time beyond what is predicted by the nonlinear factor (Figure 4 illustrates the estimates of single average growth and a single variance of the LGCM parameters, which are distinct from the observed means displayed in Figure 3). The slope loading estimates were also used in the parallel process model. The predicted trajectory of life satisfaction shows a significant decline especially between year 0 and year 5, suggesting a "honeymoon-hangover" effect, which confirms H1. There was a significant difference in the initial level of life satisfaction in the sample around a mean intercept $(-0.081, \mathrm{p}=0.006)$ and mean slope $(-0.021 ; \mathrm{p}<0.001)$. In addition, we found a significant variance of the intercept $(0.998 ; \mathrm{p}<0.001)$ and the slope $(0.162 ; p<0.001)$ confirming the variability of life satisfaction trajectories.

The multigroup analysis revealed a difference between the female and male trajectories. The parameter estimates showed a mean intercept of $-0.145(\mathrm{p}<0.001)$ and a mean slope of -0.035 $(p<0.001)$, indicting a slight downward trajectory for males. The mean intercept of $0.020(p$ $<0.001)$ and a mean slope of $-0.020(\mathrm{p}<0.001)$ indicated a modest downward trajectory for females. The analysis of variance in the trajectory of life satisfaction showed that the variability in the initial status and the growth rate of life satisfaction were significant for both males and females, indicating the presence of gender differences in the growth of life satisfaction.

- Insert Table 4 here -

- Insert Figure 4 here -

\subsection{Parallel Process Model}

The parallel process model showed a good fit with data as detailed in Table 5. In Model-A, we estimated the effect of the intercept and slope of PSS on the intercept and slope of life satisfaction. In both cases, there was a statistically significant positive effect. This indicates that the initial level of PSS is related to the initial level of life satisfaction $(\beta=0.555 ; p<0.001)$ 
and that the change of PSS is related to the change of life satisfaction $(\beta=0.680 ; p<0.001)$, thus supporting $\mathrm{H} 2 \mathrm{a}$ and $\mathrm{H} 2 \mathrm{~b}$.

In Model-B (Table 5), we estimated the effect of the initial status of PSS on the change of life satisfaction. The results indicate that any increase in the level of PSS in the initial phase will slow the decline of life satisfaction $(\beta=-0.056 ; p<0.001)$. Comparing the two nested models using the likelihood ratio $\chi^{2}$ difference test $\left(\Delta \chi^{2}=34.551 ; \Delta \mathrm{df}=1 ; \mathrm{p}<0.001\right)$; suggests that adding the extra parameter (i.e the path from the intercept of social support to the slope of life satisfaction) is significant. These results further support $\mathrm{H} 2 \mathrm{~b}$.

When comparing between male and female entrepreneurs, the significant relationship between the intercept and slope of both processes remained, lending support to H3a (Table 6). However, the effect of the initial level of perceived social support on the change rate of life satisfaction (Model-B, Table 6) was significant only for female entrepreneurs $(\beta=-0.155 ; \mathrm{p}<0.001)$ and not for males $(\beta=-0.028 ; p>0.050)$. The gender moderation test reveals that females and males differ significantly with respect to the impact of the initial level of social support on life satisfaction $\left(\Delta \chi^{2}=13.712 ; \Delta d f=8 ; p=0.022\right)$; partially supporting $H 3 b$. This means that the female entrepreneurs value social support more than male counterparts, and as they feel socially connected, they enjoy higher life satisfaction and experience a smaller decline over time.

- Insert Table 6 here

\section{Discussion and Conclusion}

457 In this study we examine the role of PSS on entrepreneur life satisfaction during the transition 458 into self-employment and beyond. Drawing on the Job Demands-Resources (JD-R) model, we argued that PSS is a key resource for entrepreneurs to cope with stressful situations, especially during the transition into self-employment. We adopted a sophisticated and rigorous approach, LGCM, to show that PSS is associated with changes in life satisfaction and to uncover how gender affects this co-development process over time.

463 Our findings provide evidence of a boost in life satisfaction in the transition phase, followed 464 by a declining trend in the years that follow. This is in line with recent research on life satisfaction and entrepreneurship entry (Georgellis and Yusuf, 2016; Hanglberger and Merz, 
2015; van der Zwan et al., 2018). Our results suggest that the "honeymoon-hangover effect" or "adaption process" (Boswell et al, 2005; 2009), does not just affect employees changing jobs but is applicable to nascent entrepreneurs as well. These findings also challenge the traditional assumption that entrepreneurs are generally highly satisfied (Benz and Frey , 2008; Schneck, 2014). Indeed, our analysis provides a contrasting picture, showing that the increase in life satisfaction is temporary, and that becoming an entrepreneur is often not the rosy, lifeimproving experience often portrayed by scholars and the public media alike. In addition, our findings extend the JD-R and JDC theory by examining the transition into selfemployment, a typically "active job". Specifically, it appears that job decision latitude only partially buffers against the negative effects of high demands of the entrepreneur's job. This lends support to the recent literature, which has cast doubts about the predictive value of the buffer hypothesis (Binder and Coad, 2016; van der Zwan et al., 2018).

The analysis confirmed our prediction that the longitudinal effects of PSS on entrepreneur life satisfaction are statistically significant, and that both the initial perception and evolution of PSS are positively related to life satisfaction over time. In line with JD-R, our results suggest that PSS can serve as a strong personal buffer, especially in stressful times (Boz Semerci and Volery, 2018). Entrepreneurs who reported a higher initial level of social support experienced less decline in life satisfaction after their transition into self-employment, perhaps because the emotional, informational, and physical resources drawn from their social network helped them to persist after launching their business. In other words, PSS helps mitigate the "hangover effect" that follows job change (Boswell et al., 2005). In particular, social support can help entrepreneurs manoeuvre the numerous hurdles (e.g., resource constraints, legal challenges, lack of reputation) in the early stages of their start-up. Our findings therefore contribute to the JD-R model, showing that PSS translates into higher levels of life satisfaction, which can potentially prevent job disengagement (Bakker and Demerouti 2007; Demerouti and Bakker, 2011). This is all the more important given that entrepreneurs often have a very low propensity for help-seeking behaviour (Williams et al., 2019). Individuals who switch to self-employment should therefore carefully map and build a strong social network that can help them weather the challenges and setbacks in their new job. The results indicate that the perception of a strong social network reducing job demands that are associated with starting a new venture is pertinent. This means that social support may enhance nascent entrepreneur ability to cope with "occupational loneliness", a perennial issue in selfemployment (Fernet et al., 2016). Identifying social support is the first step in building a more 
comprehensive resource kit that helps entrepreneurs to handle their job demands and achieve 500 their personal objectives.

501 Our multigroup analysis indicated that gender matters. This suggests that perceived social 502 support is more important for females than for males and that social support enhances life 503 satisfaction for females as they transition to self-employment and beyond. These findings 504 confirm that gender has an important influence on support-relevant social interactions, thereby 505 affecting the seeking and giving of social support in personal relations (Matud et al., 2003).

506 Female entrepreneurs appear to be opportunistic in the way they leverage their social support and mobilise resources within their network, especially during stressful events such as launching a new business venture (Johansson et al., 2016).

509 Policy-makers interested in promoting entrepreneurship and improving entrepreneur well510 being outcomes should adopt a customised approach based on gender. Furthermore, they need 511 to focus on the quality of entrepreneur social relationships and aim at influencing would-be 512 entrepreneur's mind-sets, since PSS is a cognitive assessment of the existence of the supportive 513 network. Accordingly, the development of socialisation programs that target female 514 entrepreneurs developing their feelings of relatedness and social connection could potentially improve their life satisfaction.

516 Our findings have practical implications for entrepreneurs too. Since PSS is a strong buffering 517 mechanism that helps mitigate job demands, entrepreneurs need to be proactive in building a 518 strong network. Stakeholders in the entrepreneurship ecosystems and educators can play a 519 significant role by helping entrepreneurs overcome the sense of loneliness and isolation during 520 their venture creation. The emergence of co-working spaces that allow entrepreneurs to work 521 alongside their peers, to share different business ideas, and to network with a variety of stakeholders is a step in the right direction to develop social support.

523 There are a number of limitations in this study. Firstly, as in all panel studies, sample attrition 524 is inevitable, and selection bias might occur. Nevertheless, we tried to overcome this limitation 525 by using LGCM modelling, a technique that has tolerance to missing values (Preacher et al., 526 2008). Additionally, since the research focuses on five years after the transition to self527 employment, a potential sampling bias might arise. The entrepreneurs who survive the first 528 five years are those who may have a strong positive perception about their network support. 529 Secondly, although our study was based on a large and diverse sample of Australians, the 530 generalisability of the research findings may be problematic. Future research needs to verify to 
531

532

533

534

535

536

537

538

539

540

541

542

543

544

545

546

547

548

549

550

551

552

553

554

555

556

557

558

559

560

561

562

what extent these results can be extrapolated to other contexts within different cultural and institutional frameworks. Thirdly, PSS in HILDA is a unidimensional scale, capturing mainly emotional social support. Future research may explore a different mode of social support, such as instrumental or financial support, which may have different effects on an individual's life satisfaction. Another research avenue might be to rely on a richer data set to provide a more granular picture of the impact of PSS during the transition into self-employment. Ethnographic studies drawing on in-depth interviews with key informants, observations or diary studies might provide further insight about how entrepreneurs mobilise their social network to help them weather through the ups and downs during start-up and remain happy.

\section{Acknowledgement}

The author thanks the editor and two anonymous referees of this journal, as well as Doina Olaru for considered and constructive comments and assistance in the preparation of this article.

\section{References}

Ahl, H. (2006), "Why research on women entrepreneurs needs new directions", Entrepreneurship: Theory and Practice, Vol. 30 No.5, pp. 595-621.

Andersson, P. (2008), "Happiness and health: Well-being among the self-employed", Journal of Socio-Economics, Vol. 37 No. 1, pp. 213-236.

Åstebro,T. and Chen, J. (2014), “The entrepreneurial earnings puzzle: Mismeasurement or real?", Journal of Business Venturing, Vol. 29 No. 1, pp. 88-105.

Arbuckle, J. L. (2014), “Amos (Version 23.0)”, [Computer Program], Chicago: IBM SPSS.

Bakker, A. B., Boyd, C. M., Dollard, M., Gillespie, N., Winefield, A. H., and Stough, C. (2010), "The role of personality in the job demands-resources model", Career Development International, Vol. 15 No. 7, pp. 622-636.

Bakker, A. B., Demerouti, E., and Euwema, M. C. (2005), "Job resources buffer the impact of job demands on burnout", Journal of Occupational Health Psychology, Vol. 10 No. 2, p. 170.

Bakker, A. B. and Demerouti, E. (2007), “The job demands-resources model: State of the art”, Journal of Managerial Psychology, Vol. 22 No. 3, pp. 309-328.

Barrera, M. (1986), "Distinctions between social support concepts, measures, and models", American Journal of Community Psychology, Vol. 14 No. 4, pp. 413-445. 
563

564

565

566

567

568

569

570

571

572

573

574

575

576

577

578

579

580

581

582

583

584

585

586

587

588

589

590

591

592

593

594

595

596

Benz, M. and Frey, B. S. (2008), "Being Independent is a Great Thing: Subjective Evaluations of Self-Employment and Hierarchy”, Economica, Vol. 75 No. 298, pp. 362-383.

Binder, M. (2018), “Entrepreneurial Success and Subjective Well-Being: Worries About the Business Explain One's Well-Being Loss from Self-Employment”, SOEPpaper No. 947. Available at SSRN: https://ssrn.com/abstract=3100865

Binder, M. and Coad, A. (2013), "Life satisfaction and self-employment: A matching approach”, Small Business Economics, Vol. 40 No. 4, pp. 1009-1033.

Binder, M. and Coad, A. (2016), "How Satisfied are the Self-Employed? A Life Domain View", Journal of Happiness Studies, Vol. 17 No. 4, pp. 1409-1433.

Bird, M. and Wennberg, K. (2016), "Why family matters: The impact of family resources on immigrant entrepreneurs' exit from entrepreneurship", Journal of Business Venturing, Vol. 31 No. 6, pp. 687-704.

Blanchflower, D. G. (2000), "Self-employment in OECD countries”, LabourEconomics, Vol. 7 No. 5, pp. 471-505.

Boswell, W. R., Shipp, A. J., Payne, S. C., and Culbertson, S. S. (2009), "Changes in newcomer job satisfaction over time: Examining the pattern of honeymoons and hangovers", Journal of Applied Psychology, Vol. 94 No. 4, pp. 844-858.

Boswell, W. R., Boudreau, J. W. and Tichy, J. (2005), “The relationship between employee job change and job satisfaction: The honeymoon-hangover effect", Journal of Applied Psychology, Vol. 90 No. 5, pp. 882-892.

Boz Semerci, A. and Volery, T. (2018), "Entrepreneurs as parents: the antecedents and consequence of parenting stress", International Journal of Entrepreneurial Behaviour and Research, Vol. 24 No. 1, pp. 41-58.

Cabrera, E. M. and Mauricio, D. (2017), “Factors affecting the success of women's entrepreneurship: a review of literature", International Journal of Gender and Entrepreneurship, Vol. 9 No. 2, pp. 31-65.

Cassar, G. (2010), “Are individuals entering self-employment overly optimistic? An empirical test of plans and projections on nascent entrepreneur expectations", Strategic Management Journal, Vol. 31 No. 8, pp. 822-840.

Cardon, M.S. and Patel, P.C. (2015), "Is stress worth it? Stress-related health and wealth trade-offs for entrepreneurs", Applied Psychology, Vol. 64 No. 2, pp. 379-420.

Carree, M. A. and Verheul, I. (2012), "What Makes Entrepreneurs Happy? Determinants of Satisfaction Among Founders", Journal of Happiness Studies, Vol. 13 No. 2, pp. 371387. 
Chadi, A. and Hetschko, C. (2017), "The magic of the new: How job changes affect job Satisfaction”, Journal of Economics and Management Strategy', Vol. 27 No. 1, pp. 2339.

Chadwick, I. C., and Raver, J. L. (2019), "Not for the faint of heart? A gendered perspective on psychological distress in entrepreneurship", Journal of Occupational Health Psychology, Vol. 24 No. 6, pp. 662-674.

Clarke, J. S., and Holt, R. (2016), "Imagery of ad-venture: drawing out metaphors of the entrepreneurship process", Academy of Management Proceedings, No. 1, p. 13815.

Cowling, M., Taylor, M., and Mitchell, P. (2004), "Job creators", The Manchester School, Vol.72 No. 5, pp. 601-617.

Crum, M. and Chen, Y. (2015), "Self-employment and subjective well-being: A multicountry analysis", International Journal of Entrepreneurship, Vol. 19, pp. 15-26.

Curran, P. J., Obeidat, K. and Losardo, D. (2010), “Twelve Frequently Asked Questions About Growth Curve Modeling”, Journal of Cognition and Development, Vol. 11 No. 2, pp. 121-136.

Davidson, M. J., Fielden, S. L., and Omar, A. (2010), "Black, Asian and minority ethnic female business owners: discrimination and social support", International Journal of Entrepreneurial Behavior and Research, Vol. 16 No. 1, pp. 58-80.

de Lange, A., Taris, T., Kompier, M. A. J., Houtman, I., and Bongers, P. (2003), “The very best of the millennium: Longitudinal research and the demand-control-support model”, Journal of Occupational Health Psychology, Vol. 8 No. 4, pp. 282-305.

Demerouti, E. and Bakker, A. B. (2011), “The job demands-resources model: Challenges for future research", Journal of Industrial Psychology, Vol. 37 No. 2, pp.01-09.

Dijkhuizen, J., Gorgievski, M., van Veldhoven, M., and Schalk, R. (2017), “Well-Being, personal success and business performance among entrepreneurs: A two-wave study”, Journal of Happiness Studies, Vol. 19, pp. 2187-2204.

Eagly, A. H. (1997), "Sex differences in social behavior: Comparing social role theory and evolutionary psychology", American Psychologist, Vol. 52 No. 12, pp. 1380-1383.

Eib, C. and Siegert, S. (2019), "Is female entrepreneurship only empowering for single women? Evidence from France and Germany", Social Sciences, Vol. 8 No. 4.

Failla, V., Melillo, F., and Reichstein, T. (2017), "Entrepreneurship and employment stability: Job matching, labour market value, and personal commitment", Journal of Business Venturing, Vol. 32 No. 2, pp. 162-177.

Fernet, C., Torrès, O., Austin, S., and St-Pierre, J. (2016), "The psychological costs of owning 
and managing an SME: Linking job stressors, occupational loneliness, entrepreneurial orientation, and burnout", Burnout Research, Vol. 3 No. 2, pp. 45-53.

Fuhrer, R. and Stansfeld, S. A. (2002), "How gender affects patterns of social relations and their impact on health: a comparison of one or multiple sources of support from "close persons", Social Science and Medicine, Vol. 54 No. 5, pp. 811-825.

Georgellis, Y. and Yusuf, A. (2016), "Is Becoming Self-Employed a Panacea for Job Satisfaction? Longitudinal Evidence from Work to Self-Employment Transitions", Journal of Small Business Management, Vol. 54, pp. 53-76.

Hahn, E., Specht, J., Gottschling, J., and Spinath, F. (2015), “Coping with Unemployment: The Impact of Unemployment Duration and Personality on Trajectories of Life Satisfaction", European Journal of Personality, Vol. 29 No. 6, pp. 635-646.

Hanglberger, D. and Merz, J. (2015), “Does self-employment really raise job satisfaction? Adaptation and anticipation effects on self-employment and general job changes", Journal for Labour Market Research, Vol. 48 No. 4, pp. 287-303.

Henderson, S., Duncan-Jones, P., McAuley, H., and Ritchie, K. (1978), “The patient's primary group”, British Journal of Psychiatry, Vol. 132, pp. 74-86.

Jamal, M. (1997), "Job Stress, Satisfaction, and Mental Health: An empirical Examination of Self- Employed and Non-Self-Employed Canadians", Journal of Small Business Management, Vol. 35 No. 4, pp. 48-57.

Johansson Sevä, I., Vinberg, S., Nordenmark, M., and Strandh, M. (2016), “Subjective wellbeing among the self-employed in Europe: macroeconomy, gender and immigrant status", Small Business Economics, Vol. 46 No. 2, pp. 239-253.

Kar, B. (2017), "Entrepreneurial Persistence and Exit: An Empirical Investigation”, 12th Biennial Conference on Entrepreneurship by Entrepreneurship Development, available at http://library.ediindia.ac.in:8181/xmlui/handle/123456789/5964

Karasek, R. A. (1979), “Job demands, job decision latitude, and mental strain: Implications for job redesign", Administrative Science Quarterly, Vol. 24 No.2, pp. 285-308.

Keat, O. Y., Selvarajah, C., and Meyer, D. (2011), "Inclination towards entrepreneurship among university students : An empirical study of Malaysian university students", International Journal of Business and Social Science, Vol. 2 No.15, pp. 206-220.

Lakey, B. (2013), "Perceived social support and happiness: The role of personality and Relational Processes", In Oxford Handbook of Happiness, Vol.1 No. 16.

Levine, R. and Rubinstein, Y. (2017), "Smart and illicit: who becomes an entrepreneur and do they earn more?", The Quarterly Journal of Economics, Vol. 132 No. 2, pp. 963-1018. 
Liebler, C. A. and Sandefur, G. D. (2002), "Gender differences in the exchange of social support with friends, neighbors, and co-workers at midlife", Social Science Research, Vol. 31 No. 3, pp. 364-391.

McDowell, W. C., Matthews, L. M., Matthews, R. L., Aaron, J. R., Edmondson, D. R., and Ward, C. B. (2019), "The price of success: balancing the effects of entrepreneurial commitment, work-family conflict and emotional exhaustion on job satisfaction", International Entrepreneurship and Management Journal, Vol. 15 No. 4, pp.11791192.

Matud, M. P., Ibañez, I., Bethencourt, J. M., Marrero, R., and Carballeira, M. (2003), "Structural gender differences in perceived social support", Personality and Individual Differences, Vol. 35 No. 8, pp. 1919-1929.

Marlow, S. (1997), “Self-employed women: new opportunities, old challenges?”, Entrepreneurship and Regional Development, Vol. 9 No. 3, pp. 199-210.

Marshall, N.L. and Barnett, R.C. (1993), "Work-family strains and gains among two-earner couples", Journal of Community Psychology, Vol. 21 No. 1, pp. 64-78.

Milner, A., Krnjacki L., Butterworth P., and LaMontagne, D., A. (2016), “The role of social support in protecting mental health when employed and unemployed: A longitudinal fixed-effects analysis using 12 annual waves of the HILDA cohort", Social Science and Medicine', Vol. 153, pp. 20-26.

Nahrgang, J. D., Morgeson, F. P., and Hofmann, D. A. (2011), "Safety at work: a meta-analytic investigation of the link between job demands, job resources, burnout, engagement, and safety outcomes", Journal of Applied Psychology, Vol. 96 No. 1, pp. 71.

Nguyen, H. and Sawang, S. (2016), "Juggling or struggling? Work and family interface and its buffers among small business owners", Entrepreneurship Research Journal, Vol. 6 No. 2, pp. 207-246.

Nikolova, M. (2018), "Switching to self-employment can be good for your health", Journal of Business Venturing, Vol. 34 No. 4, pp. 664-691.

Pettit, J. W., Roberts, R. E., Lewinsohn, P. M., Seeley, J. R., and Yaroslavsky, I. (2011), "Developmental relations between perceived social support and depressive symptoms through emerging adulthood: Blood is thicker than water", Journal of Family Psychology, Vol. 25 No. 1, pp. 127.

Preacher, K., Wichman, A.L., MacCallum, R.C. and Briggs, N.E. (2008), Latent Growth Curve Modeling. SAGE Publications, Inc.

Revilla, A. J., Pérez-Luño, A. and Nieto, M. J. (2016), "Does Family Involvement in 
Management Reduce the Risk of Business Failure? The Moderating Role of Entrepreneurial Orientation”, Family Business Review, Vol. 29 No. 4, pp. 365-379.

Rivera-Torres, P., Araque-Padilla, R. A. and Montero-Simó, M. J. (2013), “Job stress across gender: The importance of emotional and intellectual demands and social support in women", International Journal of Environmental Research and Public Health, Vol. 10 No. 1, pp. 375-389.

Schaufeli, W. B., and Bakker, A. B. (2004), “Job demands, job resources, and their relationship with burnout and engagement: A multi-sample study", Journal of Organizational Psychology and Behavior, Vol. 25 No. 3, pp. 293-315.

Schneck, S. (2014), "Why the self-employed are happier: Evidence from 25 European countries", Journal of Business Research, Vol. 67 No. 6, pp. 1043-1048.

Stephan, U. (2018), “Entrepreneurs' Mental Health and Well-Being: A Review and Research Agenda", The Academy of Management Perspectives, Vol. 32 No. 3, pp. 240-322.

The Economist (2014), "Entrepreneurs anonymous", available at: https://www.economist.com/business/2014/09/20/entrepreneurs-anonymous.

Theorell, T., and Karasek, R. A. (1996), "Current issues relating to psychosocial job strain and cardiovascular disease research", Journal of Occupational Health Psychology, Vol. 1 No.1, pp. 9.

van der Doef, M. and Maes, S. (1999), “The job demand-control (-support) model and psychological well-being: A review of 20 years of empirical research", Work and Stress, Vol. 13 No. 2, pp. 87-114.

van der Zwan, P., Hessels, J. and Rietveld, C. A. (2018), "Self-employment and satisfaction with life, work, and leisure", Journal of Economic Psychology, Vol. 64, pp. 73-88. van Woerkom, M., Bakker, A. B., and Nishii, L. H. (2016), “Accumulative job demands and support for strength use: Fine-tuning the job demands-resources model using conservation of resources theory", Journal of Applied Psychology, Vol. 101 No.1, pp. 141.

Williams, E. N., Munyon, T. P., and Fuller, R. M. (2019), "Givers, Takers, and New Venture Makers: Why Help-Seeking Processes Are Critical (and Different) for Entrepreneurs". In The Anatomy of Entrepreneurial Decisions, Springer, Cham, pp. 117-143.

Wooden, M., and Watson, N. (2007), "The HILDA survey and its contribution to economic and social research (so far)", Economic Record, Vol. 83 No. 261, pp. 208-231.

Zhu, F., Burmeister-Lamp, K., and Hsu, D. K. (2017), “To leave or not? The impact of family 
735 Table 1: Factor loading results for perceived social support (PSS) construct

\begin{tabular}{|l|l|c|c|}
\hline & Items & Factor loading & Uniqueness \\
\hline 1 & There is someone who can always cheer me up when I'm down & 0.7269 & 0.4716 \\
\hline 2 & I seem to have a lot of friends & 0.4976 & 0.7524 \\
\hline 3 & I enjoy the time I spend with the people who are important to me & 0.5132 & 0.7366 \\
\hline 4 & When I need someone to help me out, I can usually find someone & 0.7383 & 0.4549 \\
\hline 5 & When something is on my mind, just talking with the people I know & 0.5583 & 0.6883 \\
\hline 6 & I often need help from other people but can't get it (R) & 0.5727 & 0.6720 \\
\hline 7 & People don't come to visit me as often as I would like (R) & 0.7339 & 0.4614 \\
\hline 8 & I don't have anyone that I can confide in (R) & 0.5611 & 0.6852 \\
\hline 9 & I have no one to lean on in times of trouble (R) & 0.4496 & 0.7978 \\
\hline 10 & I often feel very lonely (R) & 0.5803 & 0.6633 \\
\hline
\end{tabular}

Note: $\mathrm{R}=$ reverse coded item, pooled data over the seven waves of the HILDA survey $(n=6,490)$.

737

738 Figure 1: Conceptual model

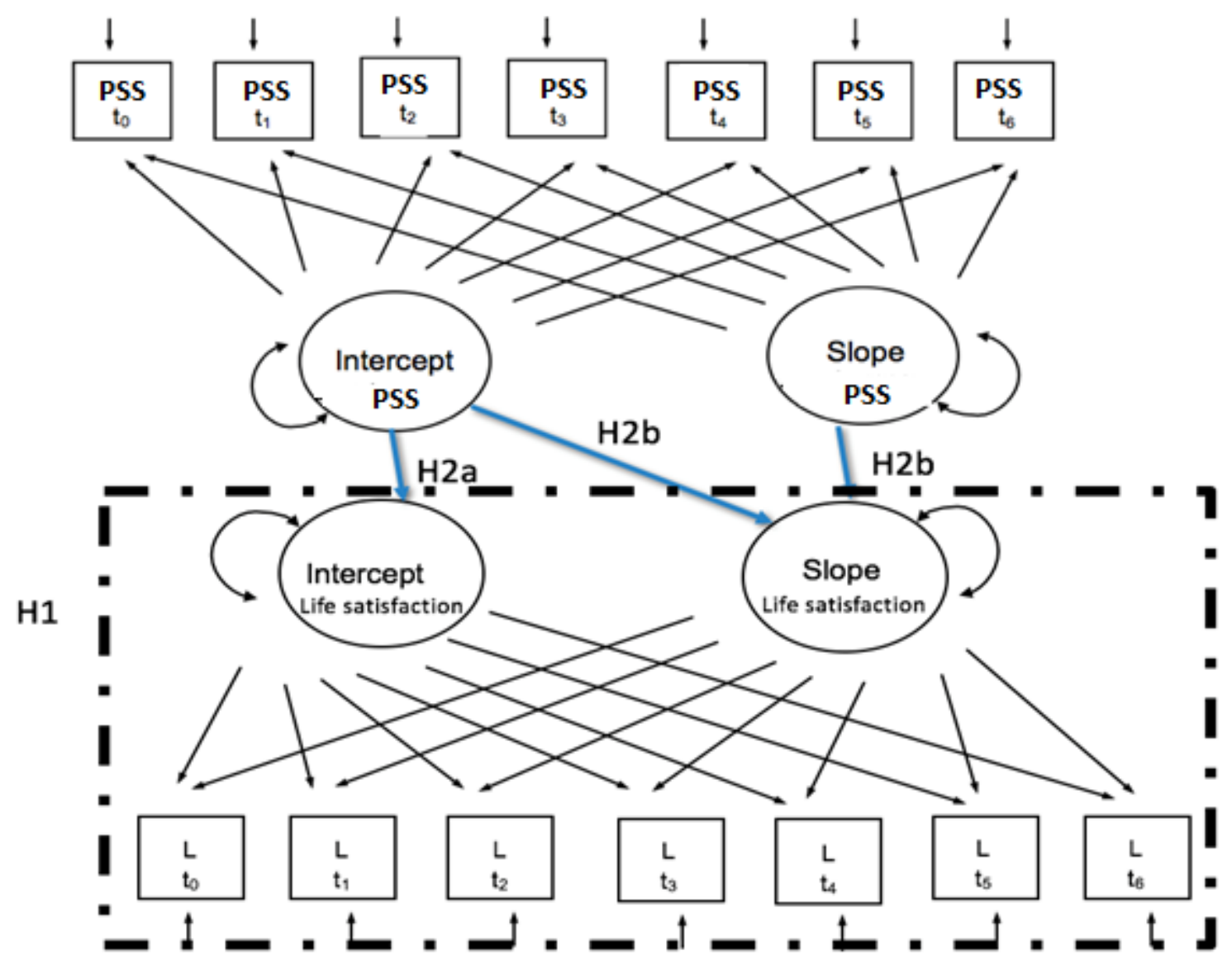

740 Note: $\mathrm{PSS}=$ perceived social support, $\mathrm{L}=$ life satisfaction, $\mathrm{t} 0$ - $\mathrm{t} 6$ represent time measurements.

741 The factor loading is fixed tol, and the slope loading varied in each model specified. 
Table 2: Demographic characteristics of the sample

\begin{tabular}{|c|c|c|c|c|c|c|c|}
\hline Sample size & $\begin{array}{c}\text { One year before } \\
\text { the transition } \\
\text { n=1303 } \\
\text { M (SD) or \% }\end{array}$ & $\begin{array}{c}\text { Transition } \\
\text { year } \\
\text { n=1303 } \\
\text { M (SD) or \% }\end{array}$ & $\begin{array}{l}\text { One year after } \\
\text { the transition } \\
\quad n=1085 \\
\text { M (SD) or \% }\end{array}$ & $\begin{array}{c}\text { Two years after } \\
\text { the transition } \\
\text { n=910 } \\
\text { M (SD) or \% }\end{array}$ & $\begin{array}{c}\text { Three years after } \\
\text { the transition } \\
\text { n=756 } \\
\text { M (SD) or \% }\end{array}$ & $\begin{array}{c}\text { Four years after } \\
\text { the transition } \\
\text { n=617 } \\
\text { M (SD) or \% }\end{array}$ & $\begin{array}{c}\text { Five years after } \\
\text { the transition } \\
\quad n=516 \\
\text { M (SD) or \% }\end{array}$ \\
\hline Age & $39(12.0)$ & $40(11.9)$ & $41(11.8)$ & $42(11.5)$ & $44(11.8)$ & $44(11.75)$ & $45(11.34)$ \\
\hline \multicolumn{8}{|l|}{ Sex } \\
\hline Male & $846(64.9 \%)$ & $846(64.9 \%)$ & $710(65.4 \%)$ & $591(64.3 \%)$ & $486(64.2 \%)$ & $395(64.0 \%)$ & $340(65.8 \%)$ \\
\hline \multicolumn{8}{|l|}{ Marital status } \\
\hline Married & $666(55.5 \%)$ & $758(58.2 \%)$ & $660(60.8 \%)$ & $586(63.9 \%)$ & $493(65.2 \%)$ & $412(66.8 \%)$ & $339(65.7 \%)$ \\
\hline $\begin{array}{l}\text { Divorced } \\
\text { Separated }\end{array}$ & $334(27.8 \%)$ & $348(26.7 \%)$ & $280(25.8 \%)$ & $243(26.5 \%)$ & $184(24.3 \%)$ & $149(24.2 \%)$ & $123(23.8 \%)$ \\
\hline Single & $200(16.7 \%)$ & $197(15.1 \%)$ & $145(13.4 \%)$ & $89(9.6 \%)$ & $79(10.5 \%)$ & $56(9.0 \%)$ & $54(10.5 \%)$ \\
\hline Income $(\log )$ & $10.43(2.1)$ & $10.15(3.2)$ & $9.70(3.9)$ & $9.86(3.8)$ & $10.04(3.4)$ & $10.25(2.9)$ & $10.32(3.1)$ \\
\hline \multicolumn{8}{|c|}{ Education completed } \\
\hline Postgraduate & $177(13.6 \%)$ & $179(13.7 \%)$ & $153(14.1 \%)$ & $134(14.6 \%)$ & $112(14.8 \%)$ & $93(15.1 \%)$ & $71(13.8 \%)$ \\
\hline Undergraduate & $347(26.6 \%)$ & $353(27.1 \%)$ & $295(27.2 \%)$ & $250(27.2 \%)$ & $213(28.2 \%)$ & $165(26.7 \%)$ & $136(26.4 \%)$ \\
\hline Vocational & $381(29.2 \%)$ & $396(30.4 \%)$ & $333(30.7 \%)$ & $272(29.6 \%)$ & $218(28.8 \%)$ & $178(28.9 \%)$ & $150(29.1 \%)$ \\
\hline Year 12 and bellow & $398(30.6 \%)$ & $375(28.8 \%)$ & $304(28.0 \%)$ & $262(28.5 \%)$ & $213(28.2 \%)$ & $181(29.3 \%)$ & $159(30.8 \%)$ \\
\hline \multicolumn{8}{|c|}{ Long-term health condition } \\
\hline Yes & $196(15.0 \%)$ & $197(15.0 \%)$ & $173(15.9 \%)$ & $148(16.1 \%)$ & $144(19.0 \%)$ & $110(17.8 \%)$ & $107(20.7 \%)$ \\
\hline \multicolumn{8}{|l|}{ Present of children } \\
\hline No children ever & $458(35.1 \%)$ & $414(31.7 \%)$ & $317(29.2 \%)$ & $230(25.0 \%)$ & $169(22.3 \%)$ & $130(21.0 \%)$ & $106(20.5 \%)$ \\
\hline
\end{tabular}


Table 3: Differences between the retained and excluded individuals, established on the baseline (the transition year) demographics

\begin{tabular}{|c|c|c|c|c|c|c|c|}
\hline & $\begin{array}{c}\text { Retained }(\mathrm{n}=1,303) \\
\quad \% \text { or } \mathrm{M}(\mathrm{SD})\end{array}$ & $\begin{array}{c}\text { excluded }(\mathrm{n}=870) \\
\% \text { or } \mathrm{M}(\mathrm{SD})\end{array}$ & $\chi^{2}$ or $t$ & p-value & Cohen's d & \multicolumn{2}{|c|}{$[95 \%$ Conf. Interval] } \\
\hline Age & $40(11.9)$ & $36.83(13.21)$ & 2.553 & 0.010 & 0.110 & 0.025 & 0.196 \\
\hline Sex (Male) & $64.9 \%$ & $57.8 \%$ & 9.269 & 0.002 & -0.132 & -0.217 & -0.047 \\
\hline \multicolumn{8}{|l|}{ Marital status } \\
\hline Married & $58.2 \%$ & $53.8 \%$ & 18.472 & 0.000 & 0.102 & 0.086 & 0.257 \\
\hline Widowed, divorced or separated & $26.7 \%$ & $27.0 \%$ & & & & & \\
\hline Single & $15.1 \%$ & $19.2 \%$ & & & & & \\
\hline Income $(\log )$ & $10.15(3.2)$ & $9.82(3.22)$ & 2.961 & 0.003 & 0.128 & 0.043 & 0.213 \\
\hline \multicolumn{8}{|l|}{ Education completed } \\
\hline Postgraduate & $13.7 \%$ & $9.0 \%$ & 10.949 & 0.012 & -0.131 & -0.217 & -0.045 \\
\hline Undergraduate & $27.1 \%$ & $24.9 \%$ & & & & & \\
\hline Vocational & $30.4 \%$ & $26.4 \%$ & & & & & \\
\hline Year 12 and below & $28.8 \%$ & $39.7 \%$ & & & & & \\
\hline Long-term health condition (Yes) & $15.0 \%$ & $16.2 \%$ & 1.688 & 0.194 & 0.056 & -0.028 & 0.1428 \\
\hline Presence of children (No) & $31.7 \%$ & $42.4 \%$ & 7.042 & 0.080 & -0.115 & -0.200 & -0.030 \\
\hline
\end{tabular}




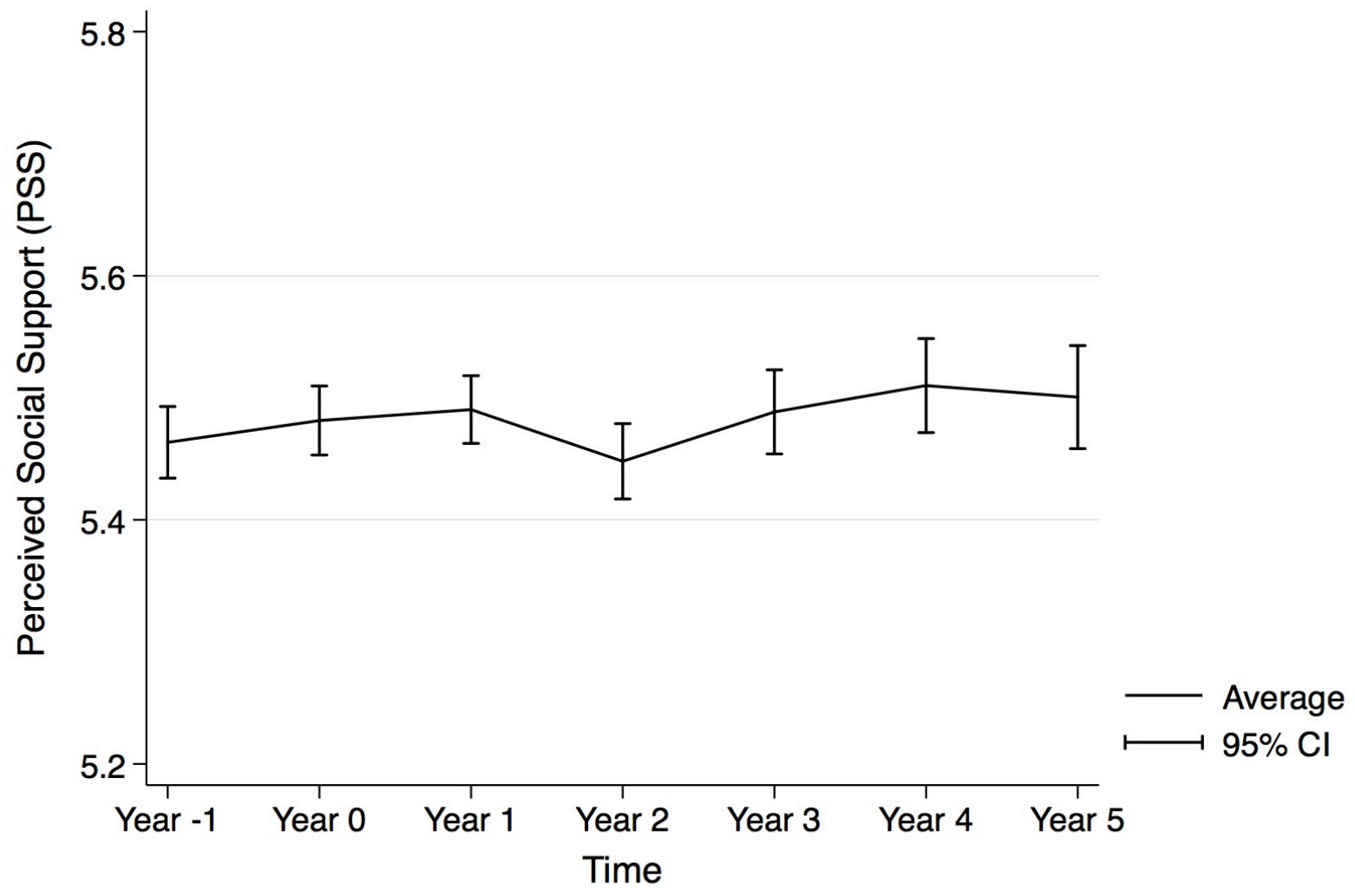




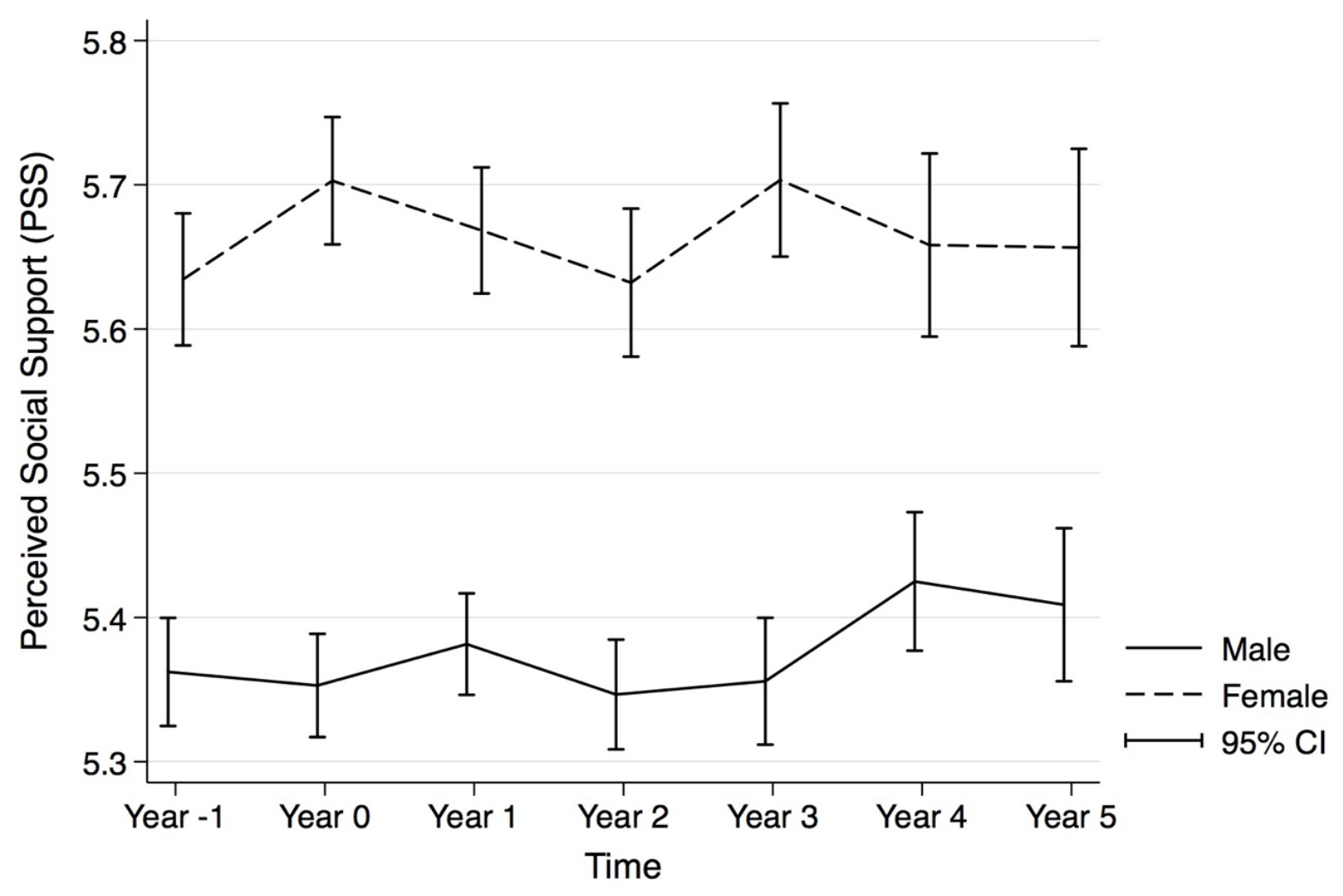




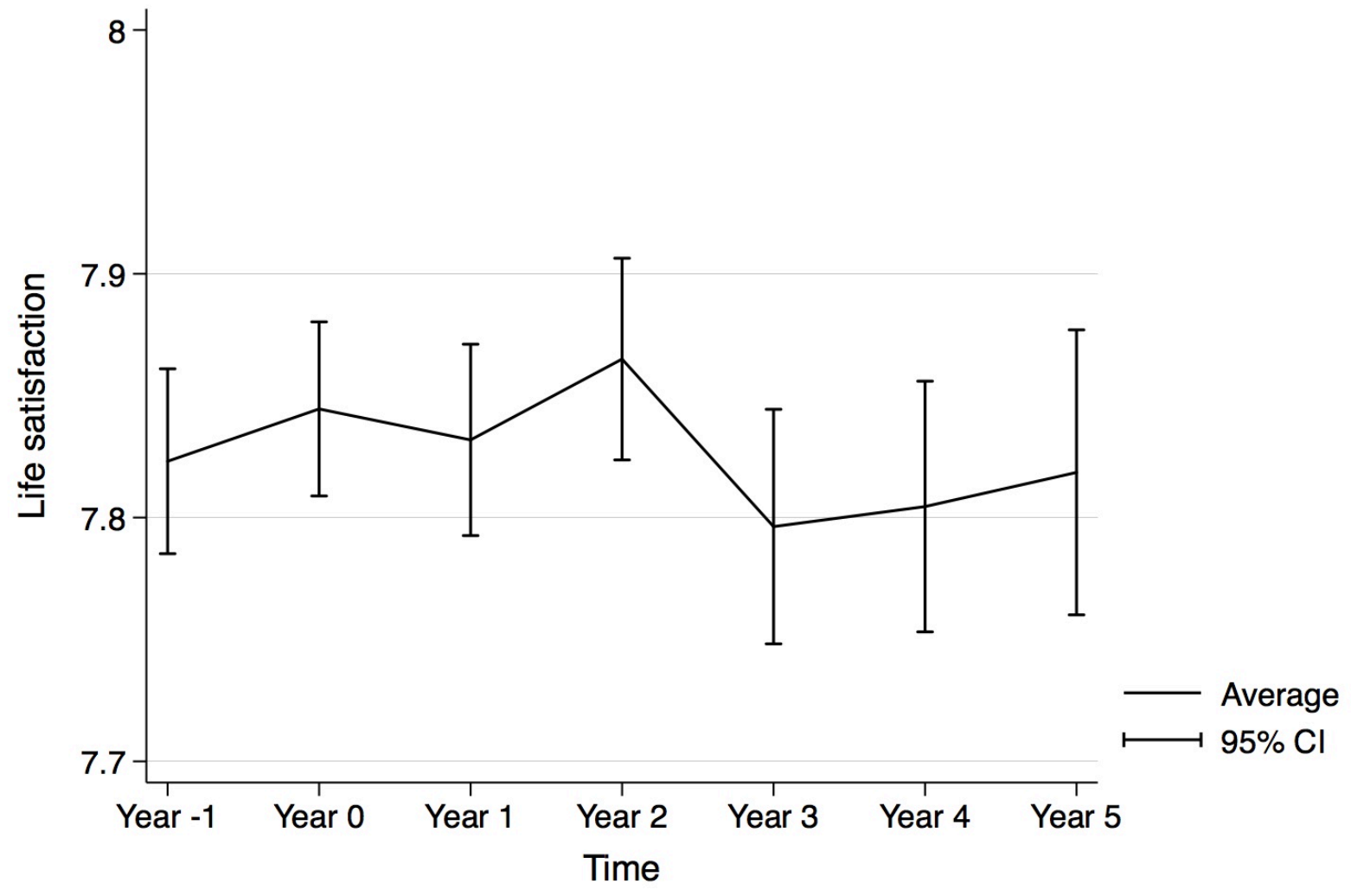




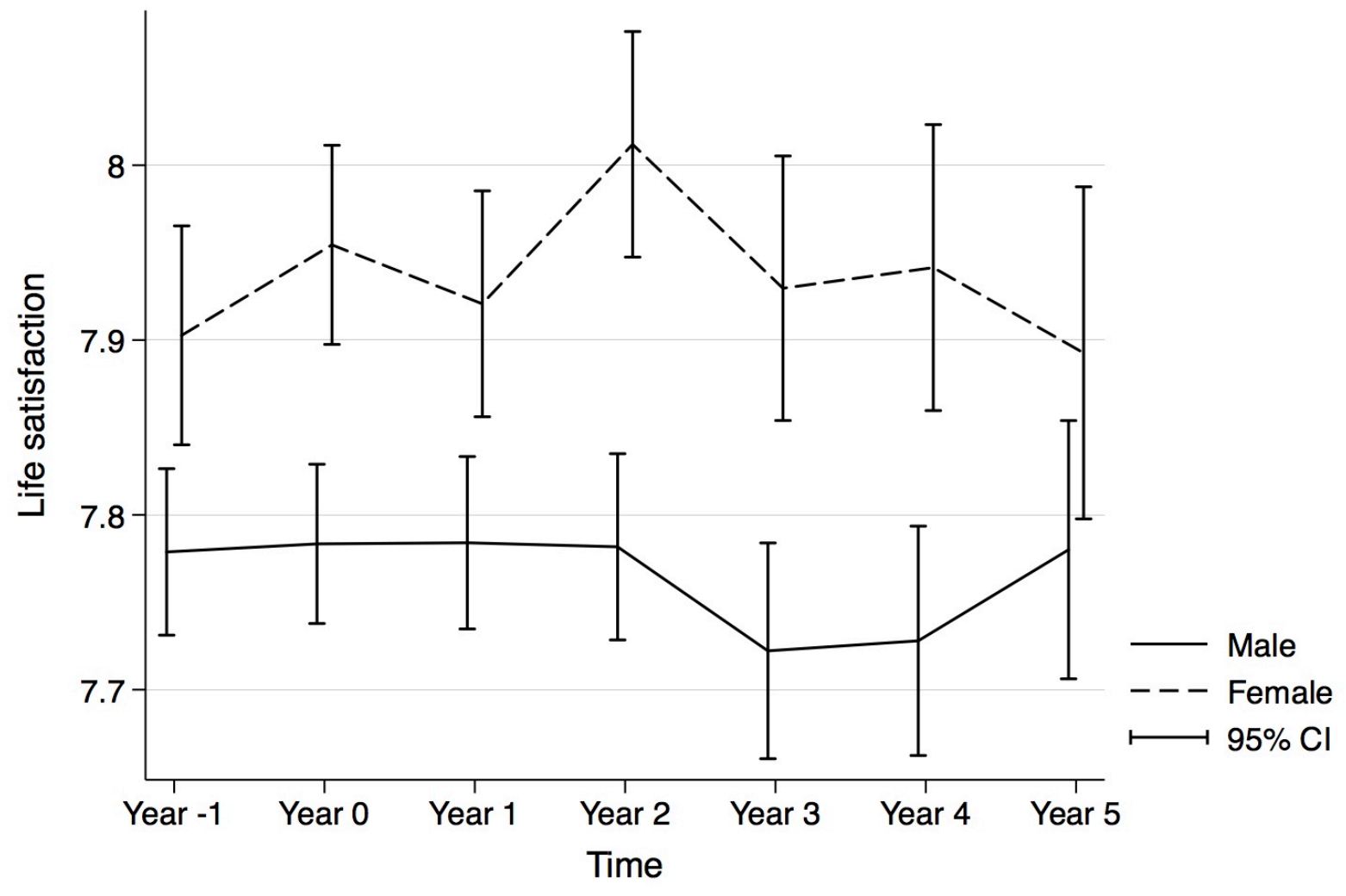

762 
Table 4: Goodness of fit for model comparison

\begin{tabular}{|c|c|c|c|c|c|c|c|c|}
\hline & $\chi^{2}(\mathrm{DF})$ & $\begin{array}{l}\text { Compared } \\
\text { With: }\end{array}$ & $\chi^{2}$ (DF) & p-value & AIC & RMSEA & TLI & CFI \\
\hline \multicolumn{9}{|l|}{ Social support } \\
\hline Free LGCM & $27.588(18)$ & & & & 61.588 & 0.020 & 0.997 & 0.996 \\
\hline Linear LGCM ${ }^{\mathbf{A}}$ & $36.245(23)$ & linear vs free & $8.657(5)$ & 0.124 & 60.245 & 0.021 & 0.995 & 0.996 \\
\hline $\begin{array}{l}\text { Nonlinear } \\
\text { LGCM }\end{array}$ & $45.636(23)$ & Quadratic vs free & $18.048(5)$ & 0.003 & 69.636 & 0.027 & 0.993 & 0.992 \\
\hline \multicolumn{9}{|l|}{ Life Satisfaction } \\
\hline Free LGCM $^{A}$ & $35.579(19)$ & & & & 64.269 & 0.022 & 0.993 & 0.996 \\
\hline Linear LGCM & $42.186(23)$ & linear vs free & $6.607(4)$ & 0.158 & 59.579 & 0.020 & 0.994 & 0.995 \\
\hline $\begin{array}{l}\text { Nonlinear } \\
\text { LGCM }\end{array}$ & $43.893(23)$ & Quadratic vs free & $1.707(4)$ & 0.789 & 67.893 & 0.026 & 0.999 & 0.992 \\
\hline
\end{tabular}

766 Note: ${ }^{\text {a }}$ model with the best model-data fit.

$767 \mathrm{LGCM}=$ latent growth curve model, $\mathrm{df}=$ degrees of freedom, $\mathrm{AIC}=$ Akaike Information Criterion, $\mathrm{RMSEA}=$ root mean square error of approximation, $\mathrm{TLI}=\mathrm{Tucker}-$

768 Lewis fit index, $\mathrm{CFI}=$ comparative fit index. In all models, invariant residual variance was assumed. 
Figure 4: The trajectory of life satisfaction with the intercept and freely estimated slope by gender

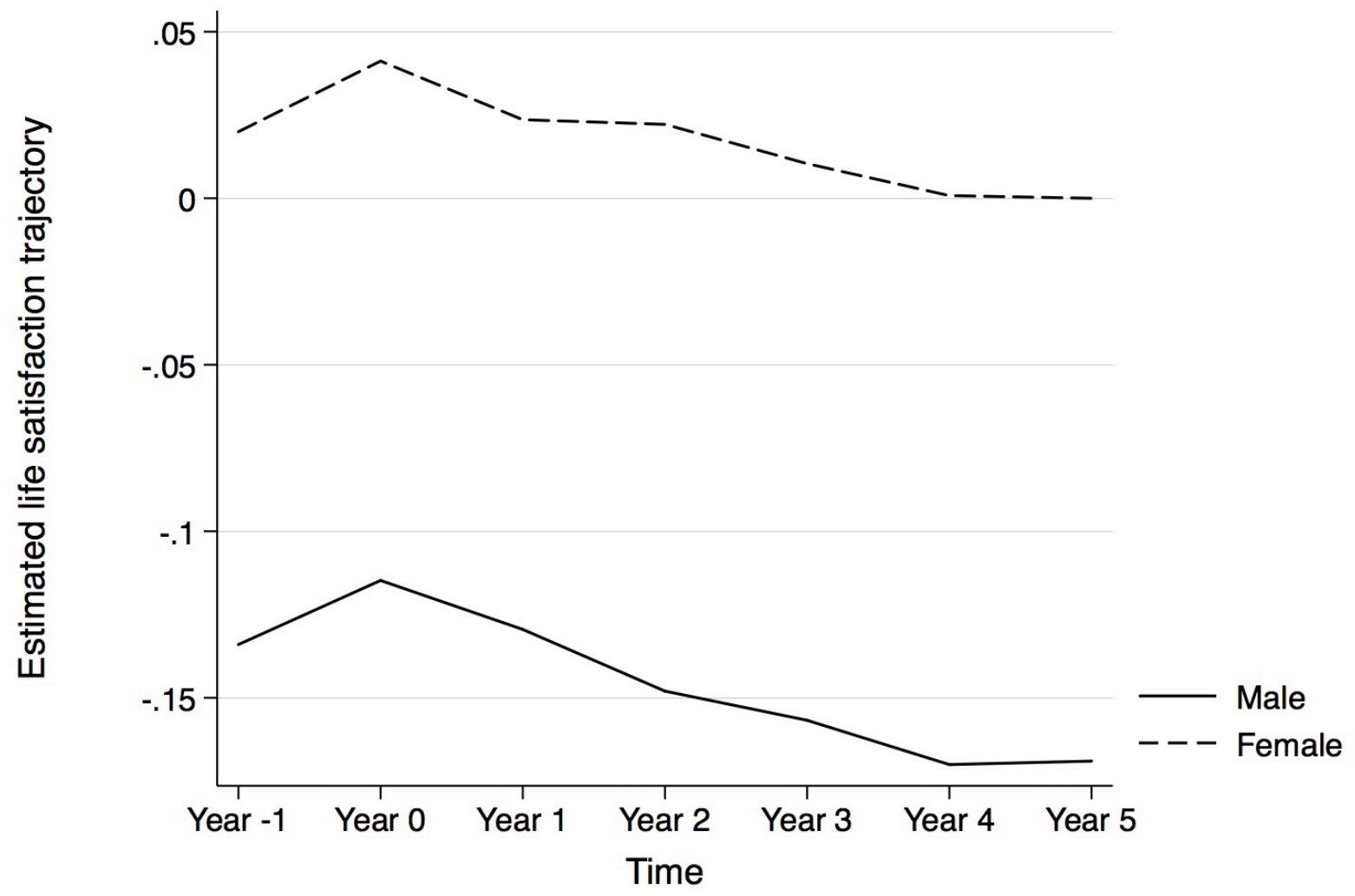

779 Note: Estimated average life satisfaction at $i$ wave $=$ mean intercept $+($ mean slope $\mathrm{x}$ unstandardized factor loading at $(i)$ wave $)$ 
Table 5: Results of the two parallel process models

\begin{tabular}{|l|c|c|}
\hline \multirow{2}{*}{ Effect of the initial of PSS $i$ on life satisfaction } & Model A & Model B \\
\cline { 2 - 3 } & $\beta($ S.E $)$ & $\beta($ S.E $)$ \\
\hline Effect of the changes of PSS $s$ on the changes of life satisfaction & $0.680 * * *(0.959)$ & $0.680 * * *(0.959)$ \\
\hline Effect of the initial of PSS $i$ on the changes of life satisfaction & & $-0.056^{* * *}(0.036)$ \\
\hline Model fit indices & & \\
$\chi^{2}$ & 233.452 & 198.901 \\
df & 99 & 98 \\
TLI & 0.974 & 0.981 \\
CFI & 0.979 & 0.984 \\
RMSEA & 0.032 & 0.028 \\
AIC & 305.452 & 272.901 \\
\hline
\end{tabular}

Note: Models are nested. $\beta=$ Standardized coefficients; $\mathrm{S} . \mathrm{E}=$ Standard error; $\mathrm{df}=$ degrees of freedom, TLI= Tucker-Lewis fit index, CFI= comparative fit index, RMSEA= root mean square error of approximation, $\mathrm{AIC}=$ Akaike Information Criterion. The models are controlling for age at the baseline. Other sociodemographic controls have been 
Table 6: Results of the two parallel process models by gender

\begin{tabular}{|c|c|c|c|c|}
\hline & \multicolumn{2}{|c|}{ Model A } & \multicolumn{2}{|c|}{ Model B } \\
\hline & \multicolumn{2}{|r|}{ Female } & \multirow{2}{*}{$\frac{\text { Male }}{\beta(\text { S.E) }}$} & \multirow{2}{*}{$\frac{\text { Female }}{\beta(\mathrm{S} . \mathrm{E})}$} \\
\hline & $\beta$ (S.E) & $\beta$ (S.E) & & \\
\hline $\begin{array}{l}\text { Effect of the initial } i \text { of PSS on life } \\
\text { satisfaction }\end{array}$ & $\begin{array}{c}0.573 * * * \\
(0.049)\end{array}$ & $\begin{array}{c}0.516^{* * *} \\
(0.063)\end{array}$ & $\begin{array}{c}0.573 * * * \\
(0.049)\end{array}$ & $\begin{array}{c}0.517^{* * *} \\
(0.063)\end{array}$ \\
\hline $\begin{array}{l}\text { Effect of the changes of PSS } s \text { on the } \\
\text { changes of life satisfaction }\end{array}$ & $\begin{array}{c}0.555^{* * *} \\
(0.894)\end{array}$ & $\begin{array}{c}0.516^{* * *} \\
(0.097)\end{array}$ & $\begin{array}{c}0.564 * * * \\
(0.911)\end{array}$ & $\begin{array}{c}0.679^{* * *} \\
(0.082)\end{array}$ \\
\hline $\begin{array}{l}\text { Effect of the initial } i \text { of PSS on the } \\
\text { changes of life satisfaction }\end{array}$ & & & $\begin{array}{l}-0.028 \\
(0.045)\end{array}$ & $\begin{array}{c}-0.155^{* * *} \\
(0.558)\end{array}$ \\
\hline \multicolumn{3}{|l|}{ Model fit indices } & \multirow{2}{*}{\multicolumn{2}{|c|}{311.162}} \\
\hline$\chi^{2}$ & \multicolumn{2}{|c|}{312.352} & & \\
\hline df & \multicolumn{2}{|c|}{198} & \multicolumn{2}{|c|}{196} \\
\hline TLI & \multicolumn{2}{|c|}{0.978} & \multicolumn{2}{|c|}{0.978} \\
\hline CFI & \multicolumn{2}{|c|}{0.982} & \multicolumn{2}{|c|}{0.982} \\
\hline RMSEA & \multicolumn{2}{|c|}{0.021} & \multicolumn{2}{|c|}{0.021} \\
\hline AIC & \multicolumn{2}{|c|}{456.352} & \multicolumn{2}{|c|}{459.162} \\
\hline
\end{tabular}

Note: Models are nested. $\beta=$ Standardized coefficients; $\mathrm{S} . \mathrm{E}=$ Standard error; $\mathrm{df}=$ degrees of freedom, TLI= Tucker-Lewis fit index, $\mathrm{CFI}=$ comparative fit index, $\mathrm{RMSEA}=$ root mean square error of approximation, AIC= Akaike Information Criterion. The models are controlling for age at the baseline. Other sociodemographics have been tested 